\title{
Developmental Changes in Presynaptic Calcium Channels Coupled to Glutamate Release in Cultured Rat Hippocampal Neurons
}

\author{
Kenneth P. Scholz and Richard J. Miller \\ Department of Pharmacological and Physiological Sciences, University of Chicago, Chicago, Illinois 60637
}

Excitatory synaptic transmission in the hippocampus involves the participation of at least two types of presynaptic $\mathrm{Ca}^{2+}$ channels, $\mathrm{N}$-type channels sensitive to $\omega$-conotoxin GVIA ( $\omega$-CTx GVIA) and Q-type channels sensitive to $\omega$-agatoxin IVA ( $\omega$-Aga IVA). Hippocampal pyramidal neurons in cell culture were used to examine the participation of these two classes of channels at different stages of synapse development. Specific $\mathrm{Ca}^{2}$ channel toxins were used to block presynaptic $\mathrm{Ca}^{2+}$ channels while whole-cell voltage-clamp recordings were used to record evoked EPSCs in postsynaptic neurons. At immature synapses (cells in culture for 10-15 d), $\omega-C T x$ GVIA (1-5 $\mu \mathrm{M})$ blocked transmission by more than $80 \%$ while $\omega$-Aga IVA ( $1 \mu \mathrm{M}$ ) was less effective. In older cultures, however, $\omega$-Aga IVA (1 $\mu \mathrm{M})$ was more effective than $\omega$-CTx GVIA (1-5 $\mu \mathrm{M})$ in blocking synaptic transmission. The pharmacological properties of the $\omega$-Aga IVA sensitive component of synaptic transmission were examined in more detail using $\omega$-Aga IVA and $\omega$-conotoxin MVIIC ( $\omega$-CTx MVIIC). The properties of this component of transmitter release indicated that a Q-type $\mathrm{Ca}^{2+}$ channel was involved in presynaptic $\mathrm{Ca}^{2+}$ entry. The results suggest that different classes of presynaptic $\mathrm{Ca}^{2+}$ channels begin to participate in transmitter release at different times during synapse development and maturation.

[Key words: $\omega$-conotoxin GVIA, $\omega$-conotoxin MVIIC, w-agatoxin IVA, glutamate, EPSC, presynaptic calcium channel]

In the CNS of many lower vertebrates, presynaptic $\mathrm{Ca}^{2+}$ channels are blocked by $\omega$-conotoxin GVIA ( $\omega$-CTx GVIA) (Rivier et al., 1987; Venema et al., 1992), a well-characterized peptide component of cone snail venom (Olivera et al., 1991). In mammals, however, $\omega$-CTx GVIA blocks only a minor fraction of transmission at many central synapses (Reynolds et al., 1986; Cruz et al., 1988; Mintz et al., 1992a). The major fraction is blocked by another $\mathrm{Ca}^{2+}$ channel toxin, $\omega$-agatoxin IVA ( $\omega$-Aga IVA) (Turner et al., 1992; Takahashi and Momiyama, 1993). For example, synaptic transmission in the rat hippocampus is partially inhibited by $\omega$-CTx GVIA (Kamiya et al., 1988; Dutar et al., 1989; Horne and Kemp, 1991; Parfitt and Madison, 1993;

\footnotetext{
Received Nov. 4, 1994; revised Jan. 11, 1995; accepted Jan. 20, 1995.

We thank W. K. Scholz for assistance in preparing neuronal cultures and W. K. Scholz and B. T. Nguyen for reading an earlier draft of the manuscript. This work supported by grants from the National Institutes of Health (R.J.M.) and from the Epilepsy Foundation of America (K.P.S.).

Correspondence should be addressed to Kenneth P. Scholz, Ph.D., Department of Pharmacology and Physiology, University of Chicago, 947 East 58 th Street, Chicago, IL 60637.

Copyright (C) 1995 Society for Neuroscience $0270-6474 / 95 / 154612-06 \$ 05.00 / 0$
}

Castillo et al., 1994; Whecler et al., 1994), although $\omega$-Aga IVA is a more effective blocker (Luebke et al., 1993; Takahashi and Momiyama, 1993; Castillo et al., 1994; Wheeler et al., 1994).

The hippocampus has been an important structure for the study of neurotransmitter action and synaptic plasticity, including facilitation and long-term potentiation (LTP). Specific forms of synaptic plasticity in the rat hippocampus have been shown to develop during a critical period around $1-2$ weeks after birth (Harris and Teyler, 1984; Muller et al., 1989; Bekenstein and Lothman, 1991). Knowledge of changes in the molecular components of synapses during differentiation of hippocampal neurons is likely to provide key insights into the function of the synapse and mechanisms of plasticity. Because $\mathrm{Ca}^{2+}$ channels are critical for triggering the release of neurotransmitter, developmental changes in the properties or identity of the presynaptic $\mathrm{Ca}^{2+}$ channel will have significant effects on the properties of synaptic transmission and plasticity. This report describes the contribution of different $\mathrm{Ca}^{2+}$ channel subtypes to excitatory synaptic transmission between cultured hippocampal pyramidal neurons at different stages of synapse development.

\section{Materials and Methods}

Cell culture. The techniques used for the preparation of cell cultures and characterization of the cultures have been described previously (Bartlett and Banker, 1984; Scholz et al., 1988; Scholz and Miller, 1991). The only difference in the culture technique was that the poly$\mathrm{L}$-lysine used as a substrate for cell adhesion to the glass coverslips was conjugated to the glass in the present study (Aplin and Hughes, 1981). This was accomplished by evaporation of 3-aminopropyltriethoxysilane onto the coverslips in a vacuum chamber overnight. This was followed by submersion of coverslips in 5\% glutaraldehyde for $2-5 \mathrm{~min}$ and four washes in distilled water. Coverslips wcre then autoclaved and placed in sterile petri dishes. Fresh poly-L-lysine $(0.05-0.1 \%$ in borate buffer) was then applied and allowed to react overnight. Criteria used for identification of pyramidal neurons have been described previously (Scholz and Miller, 1991). After the cells had grown for $15 \mathrm{~d}$ in culture, the media was supplemented with $1 \mathrm{~mm}$ kynurenic acid and $10 \mathrm{~mm} \mathrm{MgCl}_{2}$. These conditions provided optimal survival of neurons beyond this time (Furshpan and Potter, 1989).

Some of the experiments were performed on coverslips that had a growth-supporting substrate applied in a pattern to isolate single cells or pairs of cells. Patterns were constructed by a method derived from previously described techniques (Kleinfeld et al., 1988; Rohr et al., 1991). KTFR negative photoresist (PC and E, Frazer, PA; 1 part resist:2 parts thinner) was applied to the coverslips and allowed to flow to a relatively thin layer. The use of negative photoresist obviated the need to create a microscopically thin layer. The photoresist was allowed to dry and then exposed to UV light through a film mask made from Kodak LPD4 precision-line film. The coverslips were developed in KTFR developer, which removes unexposed resist. Coverslips were then exposed to 3-aminopropyltriethoxysilane as described above. The resist pattern was then removed by sonicating in xylene. From this point, the coverslips were treated with glutaraldehyde and poly-L-lysine as described above. The next day, the coverslips were washed three times in 

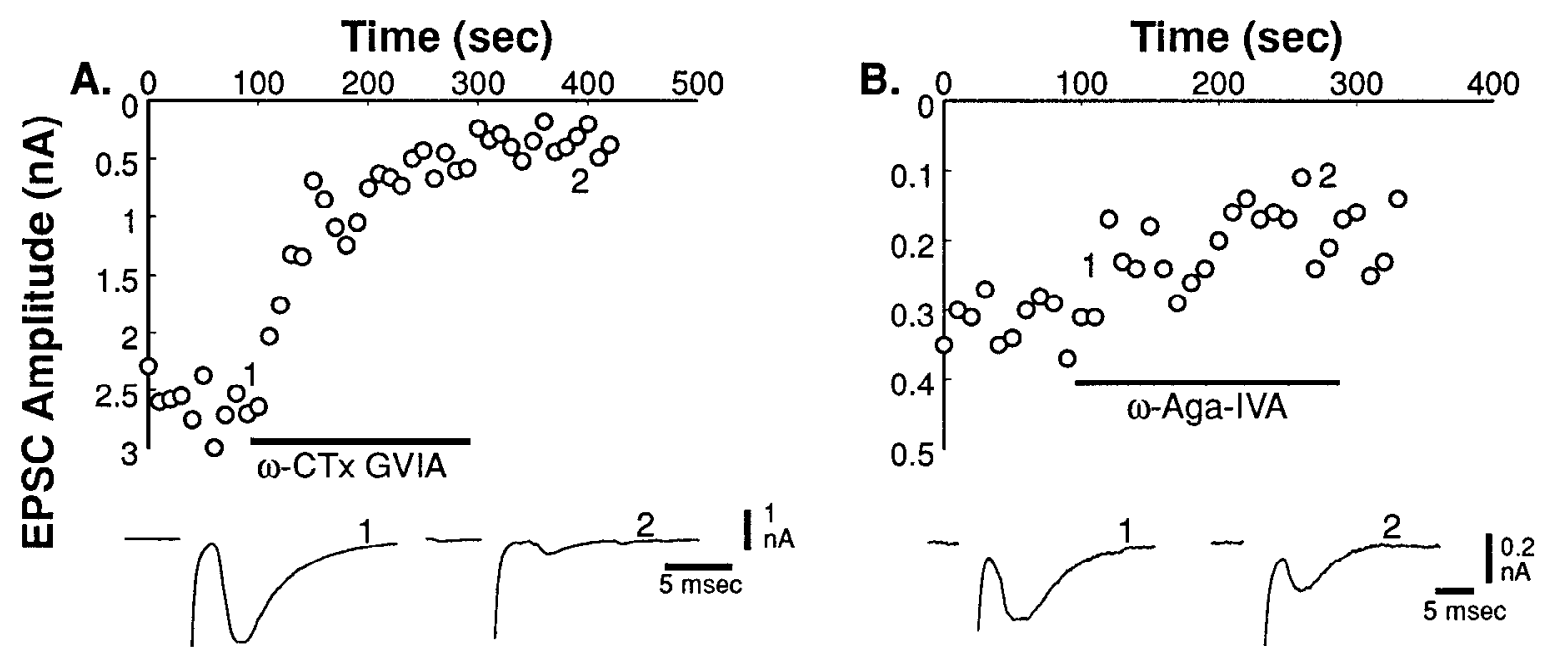

Figure 1. Block of EPSCs by $\mathrm{Ca}^{2+}$ channel toxins in immature neurons. A, Time course of block of the EPSC by $\omega$-CTx GVIA (2.5 $\left.\mu \mathrm{M}\right)$ recorded from a cell in culture for $10 \mathrm{~d}$. (Inset) EPSCs recorded at the times indicated. $(B)$ Effect of $\omega$-Aga IVA ( $\mu M$ ) on the EPSC recorded from a cell in culture for $14 \mathrm{~d}$.

$1 \mathrm{M} \mathrm{NaCl}, \mathrm{pH} 7.5$ to remove residual polylysine that was not conjugated to the surface.

Electrophysiology. Whole-cell voltage-clamp recordings were obtained from a postsynaptic neuron while a bipolar tungsten electrode was used to stimulate a presynaptic neuron. For autaptic connections, the extracellular electrode stimulated the same cell from which the whole-cell recording was obtained. For monosynaptic connections between cell pairs, the extracellular electrode stimulated a presynaptic cell from which no recording was obtained. Because in most cases there was only one presynaptic neuron, there was no ambiguity regarding the efficacy of the presynaptic stimulus. In thesc cases, the postsynaptic neuron was voltage clamped at a depolarized holding potential $(-30$ $\mathrm{mV}$ ) to inactivate $\mathrm{Na}^{+}$channels and prevent the postsynaptic neuron from firing.

For recordings of EPSCs the bath contained (in $\mathrm{mM}$ ) $\mathrm{NaCl}, 143 ; \mathrm{KCl}$, 3; $\mathrm{CaCl}_{2}, 1 ; \mathrm{MgCl}_{2}, 2$; HEPES, 10; glucose 10 at $\mathrm{pH} 7.35$ and the pipette contained (in mM) $\mathrm{K}$-fluoride, $140 ; \mathrm{MgCl}_{2}, 1$; EGTA, 10; HEPES, 10 at a $\mathrm{pH}$ of 7.15 . Intracellular fluoride was chosen as the major intracellular anion since it has been shown to reduce activation of postsynaptic voltage-gated currents, thereby allowing for a more faithful recording of EPSCs (Kay et al., 1986). Pipettes had resistances ranging from 2.0 to $3.5 \mathrm{M} \Omega$. Series resistance was $<10 \mathrm{M} \Omega$ and was corrected by $60 \%$, typically. Currents were recorded by a List EPC7 patch-clamp amplifier, filtered at $3 \mathrm{kHZ}$ and digitized at $10 \mathrm{kHZ}$. Data collection and analysis were performed by custom written programs based on Indec C-LAB subroutines (Scholz and Miller, 1991). Experiments with unstable baseline responses or obvious contamination from polysynaptic responses were discarded. EPSC amplitudes were measured from the peak of the EPSC to the baseline before the stimulus. In each case, the amplitude of 10 EPSCs was averaged for each condition. $\omega$-CTx GVIA was obtained from Peninsula Labs (Belmont, CA) and Bachem Bioscience (Philadelphia, PA). $\omega$-Aga IVA was obtained from Peptides International (Louisville, KY) and from Pfizer (Groton, CT) through Bachem Biosciences. $\omega$-CTx MVIIC was a gift from Neurex Corp. All experiments were performed at room temperature $\left(21-24^{\circ} \mathrm{C}\right)$ and in the continuous presence of $0.5 \mathrm{mg} / \mathrm{ml}$ chicken egg albumin (Sigma grade $\mathrm{V}$; a normal component of the cell culture media) in order to block lowaffinity binding sites. All toxins were applied by bath superfusion.

\section{Results}

The experiments were performed on hippocampal pyramidal neurons cultured from embryonic rats at $17 \mathrm{~d}$ gestation. Cultures prepared at this point in development are highly enriched in pyramidal neurons (Scholz and Miller, 1991). Some of the experiments were performed on coverslips that had a growth-supporting substrate applied in a pattern to isolate single cells or pairs of cells (see Materials and Methods). This procedure per- mitted experiments to be performed on cells that received synaptic input from only one presynaptic neuron. In other cases, cells were plated very sparsely (approximately 4 cells $/ \mathrm{mm}^{2}$ ). Autaptic connections (cf. Bekkers and Stevens, 1991; Segal, 1991; Pan et al., 1993), as well as monosynaptic connections between cell pairs, were used for these studies; the results were indistinguishable. Hrom previous work on this preparation (Scholz and Miller, 1991, 1992), it is known that synapses can be detected by electrophysiological methods beginning around day 7 in culture (corresponding roughly to postnatal day 2-3). By 9-10 d in culture, excitatory postsynaptic currents (EPSCs) can be observed readily and increase in prevalence and amplitude for several more days.

$\omega$-CTX GVIA is a peptide first isolated from the venom of the cone snail Conus geographus (Olivera et al., 1991). It is well characterized as a selective and high affinity blocker of N-type $\mathrm{Ca}^{2+}$ channels (Williams et al., 1992; Dubel et al., 1992; Fujita et al., 1993). In the rat hippocampus, $\omega$-CTx GVIA partially blocks synaptic transmission at Schaffer collateral synapses (Kamiya et al., 1988; Dutar et al., 1989; Horne and Kemp, 1991; Parfitt and Madison, 1993; Castillo et al., 1994; Wheeler et al., 1994). When they have been compared, $\omega$-CTx GVIA was found to be a less effective blocker than $\omega$-Aga IVA at Schaffer collateral synapses (Luebke et al., 1993; Wheeler et al., 1994). In contrast, in this study $\omega$-CTx GVIA $(1-5 \mu \mathrm{M})$ was found to be a very effective blocker of synaptic transmission between immature cultured hippocampal pyramidal neurons (Fig. 1A). In cells that were in culture for $10-15 \mathrm{~d}$ inclusive, $\omega$-CTx GVIA blocked EPSCs by $86 \pm 5 \%(n=7$; mean \pm SEM).

$\omega$-Aga IVA is another peptide $\mathrm{Ca}^{2+}$ channel toxin first isolated from the venom of the funnel web spider Agelenopsis aperta (Mintz et al., 1992a). This toxin was initially characterized as a blocker of P-type channels and transmitter release in the mammalian CNS with an affinity for P-type channels on the order of $2 \mathrm{nM}$ (Mintz et al., 1992a,b). w-Aga IVA shows no blocking activity at $\mathrm{N}$-type channels (or non- $\mathrm{Ca}^{2+}$ channels) at concentrations of $1 \mu \mathrm{M}$ or below (Mintz and Bean, 1993; Wheeler et al., 1994). Recent work has concluded that $\omega$-Aga IVA may also block another class of channels, termed Q-type $\mathrm{Ca}^{2+}$ channels, with somewhat lower affinity $\left(\mathrm{IC}_{50}\right.$ of $100-1000 \mathrm{nM}$; Sather et 

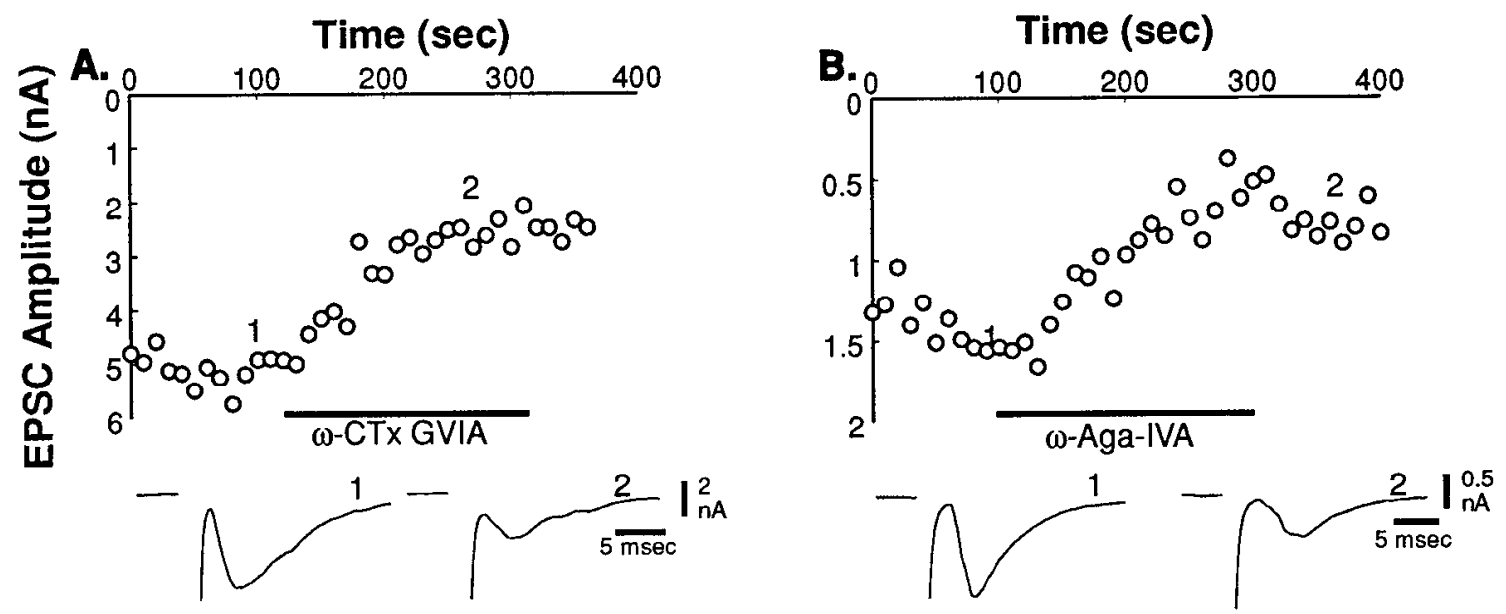

Figure 2. Block of EPSCs by $\mathrm{Ca}^{2+}$ channel toxins at a more advanced stage of synapse development. $A$, Effect of $\omega$-CTx GVIA (2.5 $\left.\mu \mathrm{M}\right)$ on the EPSC recorded from a cell in culture for $23 \mathrm{~d} . B$, Effect of $\omega$-Aga IVA $(1 \mu \mathrm{M})$ on the EPSC recorded from a cell in culture for $21 \mathrm{~d}$.

al., 1993). Such Q-type $\mathrm{Ca}^{2+}$ channels have been proposed to be responsible for the majorily of $\mathrm{Ca}^{2+}$ influx that triggers transmitter release at Schaffer collateral synapses, since the kinetics of block by $\omega$-Aga IVA at this synapse are slower than for block of P-type channels (Wheeler et al., 1994; , see also Wu and Saggau, 1994). Figure $1 B$ shows that $\omega$-Aga IVA ( $1 \mu M)$ was a much less effective blocker of synaptic transmission in immature neurons as compared to previous reports using adult synapses. The efficacy of $\omega$-Aga IVA $(1 \mu \mathrm{M})$ in blocking transmission between pyramidal neurons grown in culture for $10-15 \mathrm{~d}$, inclusive, averaged $32 \pm 9 \%(n-8)$. The source of variability in the effects of $\omega$-Aga IVA observed at this age is not clear.

As the neurons developed in culture, the efficacy by which $\omega$-CTx GVIA blocked synaptic transmission decreased (Fig. $2 A$ ), while that of $\omega$-Aga IVA increased (Fig. $2 B$ ). After the cells were in culture for $21 \mathrm{~d}$ or more, $\omega$-CTx GVIA blocked EPSCs by $30 \pm 5 \%(n=9)$. This effect was significantly less than at $15 \mathrm{~d}$ or earlier (two-tailed Mann-Whitney test, $p<$ $0.001)$. In contrast, during this same time period $\omega$-Aga IVA blocked EPSCs by $62 \pm 4 \%(n=10)$. This effect was signif-

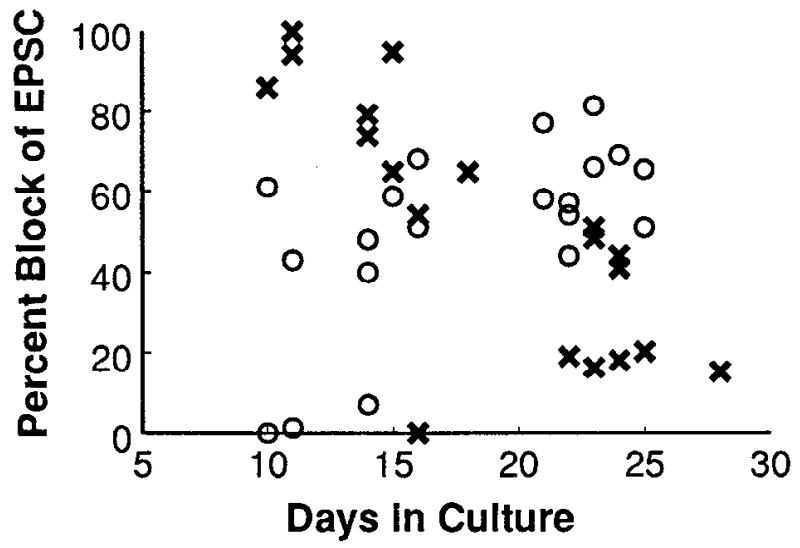

Figure 3. Summary of results showing block of EPSCs by $\mathrm{Ca}^{2+}$ channel toxins at different times in development. $X$, Percent block of the EPSC by $\omega$-CTX GVIA (1-5 $\mu \mathrm{M})$ for each cell plotted as a function of the time spent growing in culture. $O$, Percent block of the EPSC by $\omega$-Aga IVA $(1 \mu \mathrm{M})$ for each cell. Each symbol represents a different cell. The extrapolated day of birth corresponds roughly to day 4-5 in culture. icantly greater than the effect of $\omega$-Aga IVA at $15 \mathrm{~d}$ or earlier (two-tailed Mann-Whitney test, $p<0.05$ ).

Figure 3 summarizes the effects of the two toxins in cultured neurons of different ages. Notice that in immature neurons (e.g., before $15 \mathrm{~d}$ in culture), $\omega$-CTx GVIA was a more effective blocker of synaptic transmission than $\omega$-Aga IVA. In contrast, later in development (e.g., after 21 d) $\omega$-Aga IVA was the more effective blocker. These results suggest that $\mathrm{N}$-type $\mathrm{Ca}^{2+}$ channels are important for transmitter release at an early stage of synapse development. As the cells mature, a second type of $\mathrm{Ca}^{2+}$ channel is incorporated into the transmitter release pathway and eventually plays a dominant role there. This second type of channel is blocked by $1 \mu \mathrm{M} \omega$-Aga IVA.

The change in presynaptic $\mathrm{Ca}^{2+}$ channel is unlikely to be due to treatment of cells with kynurenic acid or $10 \mathrm{mM} \mathrm{Mg}^{2+}$ because it was already underway by day 15 (see Fig. 3) and because it could be observed in cells that survived up to day 18 without such treatment (data not shown). Furthermore, in threc cclls that were not treated with kynurenic acid or elevated $\mathrm{Mg}^{2+}$ and from which recordings were obtained at $23 \mathrm{~d}$ in culture, $\omega$-CTx GVIA reduced the EPSC by $24 \pm 2 \%$. This value is within the range of values observed in cells grown in kynurenic acid and elevated $\mathrm{Mg}^{2+}$ (see Discussion).

Figure $4 A$ demonstrates that the combination of $\omega$-Aga IVA $(1 \mu \mathrm{M})$ and $\omega$-CTx.GVIA $(2.5 \mu \mathrm{M})$ blocked EPSCs almost conIpletely. In three cells, all in culture more than $21 \mathrm{~d}$, the successive application of these two toxins blocked the EPSC by $83 \pm$ $5 \%$. As mentioned earlier, $\omega$-Aga IVA is thought to recognize at least two classes of channels, P-type and Q-type (Sather et al., 1993), which may be related. The $\omega$-Aga IVA sensitive channel that played a dominant role in transmitter release late in development was characterized further by the use of $\omega$-Aga IVA and another cone snail toxin $\omega$-CTx MVIIC (Hillyard et al., 1992). $\omega$-CTx MVIIC blocks a number of $\mathrm{Ca}^{3+}$ channcl subtypes including N-type channels (Hillyard et al., 1992; Grantham et al., 1994). This toxin also blocks P- and Q-type channels, and is thought to block Q-type channels with higher affinity, although the precise dose dependence is not well established (Hillyard et al., 1992; Sather et al., 1993).

For these experiments, cells in culture for more than $21 \mathrm{~d}$ were used. At the onset, $\omega$-CTx GVIA was applied at a saturating concentration to block N-type channels. This was followed 

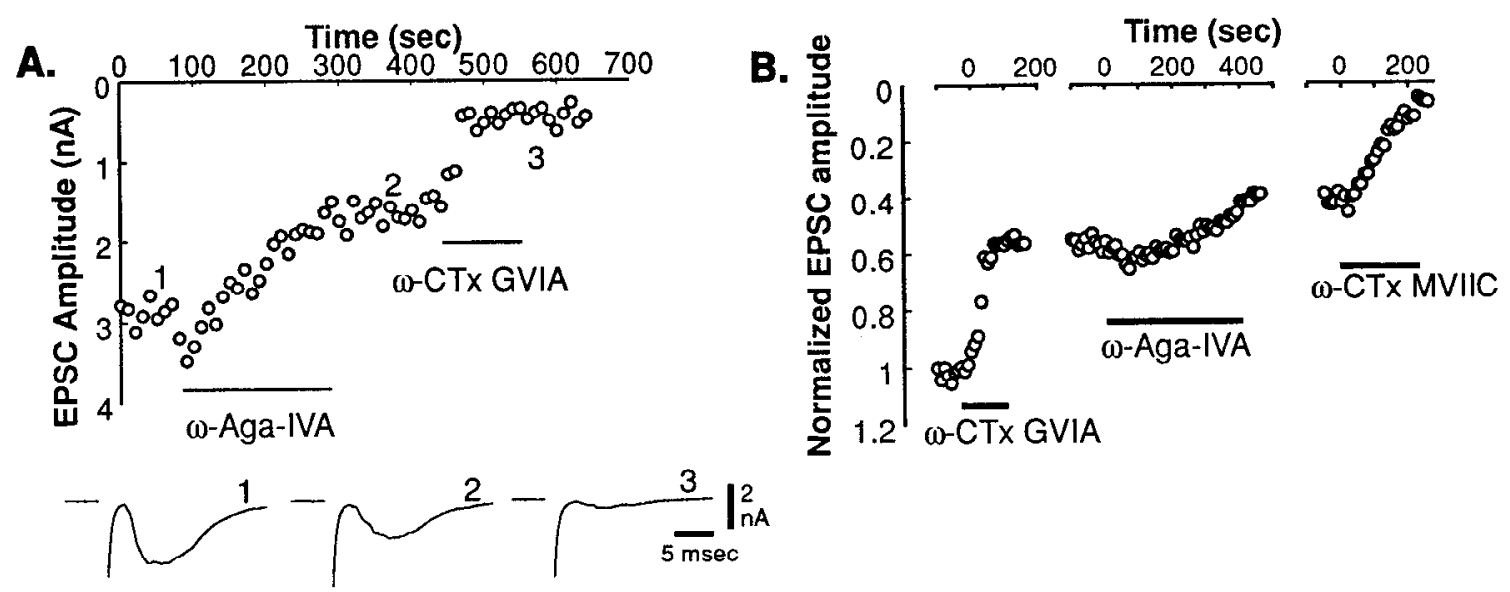

Figure 4. Pharmacological properties of the (1)-Aga IVA sensitive presynaptic Ca ${ }^{2+}$ channel. A, Application of (t)-CTx GVIA (2.5 $\mu$ M) after block of $\omega$-Aga IVA sensitive channels (cell in culture for $22 \mathrm{~d}$ ). $B$, Ensemble average of results from three cells. After block of the $\omega$-CTx GVIA sensitive component of the EPSC, a low concentration of $\omega$-Aga IVA (50 nM) produced block at a very slow rate. Subsequent application of $\omega$-CTx MVIIC ( $3 \mu \mathrm{M})$ produced a rapid and nearly complete block of the remaining synaptic current (cell in culture for $24 \mathrm{~d}$ ).

by the application of $50 \mathrm{~nm} \omega$-Aga IVA, a concentration sufficient to block P-type channels within a few minutes but that will block Q-type channels very slowly (Mintz et al., 1992b; Mintz and Bean, 1993; Sather et al., 1993; Wheeler et al., 1994). Finally, $\omega$-CTx MVIIC was applied to the remaining EPSC at a concentration of $3 \mu \mathrm{M}$. The results (Fig. $4 B$ ) indicate that the presynaptic $\mathrm{Ca}^{2+}$ channel that was resistant to block by $\omega$-CTx GVIA was blocked by $50 \mathrm{~nm} \omega$-Aga IVA at a very slow rate, consistent with the properties of a Q-type channel (see Discussion). Furthermore, $3 \mu \mathrm{M} \omega$-CTx MVIIC blocked the remaining EPSC with a time course that also suggests the participation of a Q-type channel at the presynaptic terminal. Thus, the Q-type presynaptic $\mathrm{Ca}^{2+}$ channel, previously shown to trigger transmitter release in the adult rat hippocampus, is likely to account for the presynaptic $\mathrm{Ca}^{2+}$ channel that couples to glutamate release late in development of hippocampal synapses in culture.

\section{Discussion}

The results of these studies suggest that immature excitatory hippocampal synapses utilize predominantly N-type channels for the regulation of transmitter release. During the first 1-3 weeks of postnatal life, the synapses change so as to utilize a mixture of N-and Q-type channels, with Q-type channels predominating at more mature synapses. The evidence for the participation of a Q-type channel, as opposed to a P-type channel, was obtained from an analysis of the blocking actions of $\omega$-Aga IVA and $\omega$-CTx MVIIC. It has been estimated that synthetic $\omega$-Aga IVA blocks P-type channels with a $K_{d}$ of $1.4 \mathrm{nM}$ and an on-rate of $2.4 \times 10^{5} \mathrm{M}^{-1} \mathrm{sec}^{-1}$ (Mintz and Bean, 1993). From these values, it has been calculated that $30 \mathrm{~nm}$ toxin would provide $98 \%$ block of P-type channels within $120 \mathrm{sec}$ (Wheeler et al., 1994). In contrast, Figure $4 B$ shows that 50 nm toxin produced block of the EPSC at a much slower rate. A higher concentration of $\omega$-Aga IVA ( $1 \mu \mathrm{M})$ blocked nearly all of the $\omega$-CTx GVIA insensitive transmitter release (Fig. $4 A$ ).

Although the cells were treated with $1 \mathrm{~mm}$ kynurenic acid and $10 \mathrm{~mm} \mathrm{Mg}^{2+}$ to enhance survival beyond day 15 , it is unlikely that such treatment was responsible for the developmental changes observed, since untreated cells underwent a similar change. Nevertheless, it will be important to examine the role of activity in the control of the presynaptic $\mathrm{Ca}^{2+}$ channel identity.
The possibility that activity participates in the control of the presynaptic $\mathrm{Ca}^{2+}$ channel that couples to release has not been ruled out. Furthermore, since the majority of plated cells survive when treated with kynurenic acid, the results are unlikely to arise from a change in the neuronal population resulting from selective death of specific cell populations.

Other workers have reported nonadditive effects of $\omega$-CTx GVIA and $\omega$-Aga IVA on synaptic transmission (Takahashi and Momiyama, 1993; Wheeler et al., 1994) and attributed this to the nonlinear relationship between $\mathrm{Ca}^{2+}$ entry and transmitter release (Dodge and Rahamimoff, 1967; Augustine et al., 1987). While we also see some evidence for this effect it is not as dramatic as these earlier reports. However, this issue cannot be addressed properly without adequate voltage control of the subsynaptic membrane in the postsynaptic neuron.

Developmental changes in the expression or localization of different somatic $\mathrm{Ca}^{2+}$ channels has been described in hippocampal and other neurons (Yaari et al., 1987; McCobb et al., 1989; Jones et al., 1989; Thompson and Wong, 1991; Gruol et al., 1992; Desarmenien et al., 1993). In addition, pharmacological studies in the chick have detected a developmental change in which dihydropyridine-sensitive channels contribute to transmitter release early in development but not later (Gray et al., 1992). Excitatory amino acid receptors also undergo changes during development in the CNS (cf. Williams et al., 1993, for a recent study). Indeed, changes in the expression patterns of ion channels is likely to be an extremely important feature of neuronal development.

The results raise the question whether changes in the ability of hippocampal synapses to undergo synaptic plasticity during development can be explained by developmental changes in the presynaptic $\mathrm{Ca}^{2+}$ channel. For the case of LTP, such a scenario seems unlikely, even though LIP does undergo dramatic changes during the same period of development (Harris and Teyler, 1984; Muller et al., 1989; Bekenstein and Lothman, 1991). Indeed, there is good evidence that the type of presynaptic $\mathrm{Ca}^{2+}$ channel is not important for the generation or expression of LTP, at least during the first hours (Muller and Lynch, 1989; Castillo et al., 1994; Wheeler et al., 1994). For other forms of synaptic plasticity, however, the type of presynaptic $\mathrm{Ca}^{2+}$ channel is likely to be very important. This is particularly true for $G$ protein- 
coupled presynaptic inhibition, which is likely to involve modulation of the presynaptic $\mathrm{Ca}^{2+}$ channel. It will be interesting to examine developmental changes in presynaptic inhibition at these synapses. In addition, paired-pulse facilitation changes at the same developmental period during which the presynaptic $\mathrm{Ca}^{2+}$ channel changes (Muller et al., 1989). Thus, the utilization of multiple $\mathrm{Ca}^{2+}$ channels for transmitter release is likely to be involved in the control of synaptic plasticity and neuromodulatory actions.

Other important issues raised by the results reported here involve the nature of the developmental change in the presynaptic $\mathrm{Ca}^{2+}$ channel. For instance, does each release site have a single type of $\mathrm{Ca}^{2+}$ channel or does each release site incorporate more than one type of channel? A related question is whether each newly formed release site incorporates $\mathrm{N}$-type channels first and Q-type channels later. The alternative is that the release sites formed in carly postnatal life utilize $\mathrm{N}$-type channels indefinitely whereas release sites that develop later utilize Q-type channels. In this regard, $\omega$-CTx GVIA sensitive channels and $\omega$-Aga IVA sensitive channels can be detected in the soma of cultured hippocampal neurons by the earliest times included in this study (Scholz and Miller, unpublished observations). It is also not clear whether Q-type channels are present in the presynaptic terminal of immature cells but do not contribute to release. Finally, it will be important to determine whether release sites formed anew in the adult nervous system incorporate $\mathrm{N}$-type channels first, thereby following the same developmental sequence as release sites developing in the neonatal brain.

\section{References}

Aplin JD, Hughes RC (1981) Protein-derivatised glass coverslips for the study of cell-to-substratum adhesion. Anal Biochem 113:144148.

Augustine GJ, Charlton MP, Smith SJ (1987) Calcium action in synaptic transmitter release. Annu Rev Neurosci 10:633-693.

Bartlett WP, Banker GA (1984) An electron microscope study of the development of axons and dendrites by hippocampal neurons in culture. I. Cells which develop without intercellular contacts. J Neurosci 4:1944-1953.

Bekenstein JW, Lothman EW (1991) An in vivo study of the ontogeny of long-term potentiation (ITP) in the CA 1 region and in the dentate gyrus of the rat hippocampal formation. Dev Brain Res 63:245-251.

Bekkers JM, Stevens CF (1991) Excitatory and inhibitory autaptic currents in isolated hippocampal neurons maintained in cell culture. Proc Natl Acad Sci USA 88:7834-7838.

Castillo PE, Weisskopf MG, Nicoll RA (1994) The role of $\mathrm{Ca}^{2+}$ channels in hippocampal mossy fiber synaptic transmission and long-term potentiation. Neuron 12:261-269.

Cruz LJ, Johnson DS, Imperial JS, Griffin D, LeCheminant GW, Miljanich GP, Olivera BM (1988) $\omega$-Conotoxins and voltage-sensitive calcium channel subtypes. Curr Top Membr Trans 33:417-429.

Desarmenien MG, Clendening B, Spitzer NC(1993) In vivo development of voltage-dependent ionic currents in embryonic Xenopus spinal neurons. J Neurosci 13:2575-2581.

Dodge FA Jr, Rahamimoff R (1967) Co-operative action of calcium ions in transmitter release at the neuromuscular junction. J Physiol (Lond) 193:419-432.

Dubel SJ, Starr TVB, Hell J, Ahlijanian MK, Enyeart JJ, Catterall WA (1992 Molecular cloning of the $\alpha-1$ subunit of an $\omega$-conotoxin-sensitive calcium channel. Proc Natl Acad Sci USA 89:5058-5062.

Dutar P, Rascol O, Lamour Y (1989) $\omega$-Conotoxin GVIA blocks synaptic transmission in the CA1 field of the hippocampus. Eur J Pharmacol 174:261-266.

Fujita Y, Mynlieff M, Dirksen RT, Kim M, Niidome T, Nakai J, Friedrich T, Iwabe N, Miyata T, Furuichi T, Furutama D, Mikoshiba K, Mori Y, Beam K G (1993) Primary structure and functional expression of the $\omega$-conotoxin-sensitive $\mathrm{N}$-type calcium channel from rat brain. Neuron 10:585-598.
Furshpan EJ, Potter DD (1989) Seizure-like activity and cellular damage in rat hippocampal neurons in cell culture. Neuron 3:199-207.

Grantham CJ, Bowman D, Bath CP, Bell DC, Bleakman D (1994) $\omega-$ Conotoxin MVIIC reversibly inhibits a human N-type calcium channel and calcium influx into chick synaptosomes. Neuropharmacology 33:255-258.

Gray DB, Bruses JL, Pilar GR (1992) Developmental switch in the pharmacology of $\mathrm{Ca}^{2+}$ channels coupled to acetylcholine release. Neuron 8:715-724.

Gruol DL, Deal CR, Yool AJ (1992) Developmental changes in calcium conductances contribute to the physiological maturation of cerebellar Purkinje neurons in culture. $J$ Neurosci 12:2838-2848.

Harris KM, Teyler TJ (1984) Developmental onset of long-term potentiation in area CAl of the rat hippocampus. J Physiol (Lond) 346: $27-48$.

Hillyard DR, Monje VD, Mintz IM, Bean BP, Nadasdi L, Ramachandran J, Miljanich G, Azimi-Zoonooz A, McIntosh JM, Cruz LJ, Imperial J S, Olivera BM (1992) A new conus peptide ligand for mammalian presynaptic $\mathrm{Ca}^{2+}$ channels. Neuron 9:69-77.

Horne AI, Kemp IA (1991) The effects of (1)-conotoxin GVIA on synaptic transmission within the nucleus accumbens and hippocampus of the rat in vitro. Br J Pharmacol 103:1733-1739.

Joncs OT, Kunzc DL, Angclides KJ (1989) Localization and mobility of $\omega$-conotoxin-sensitive $\mathrm{Ca}^{2+}$ channels in hippocampal CAl neurons. Science 244:1189-1193.

Kamiya H, Sawada S, Yamamoto C (1988) Synthetic $\omega$-conotoxin blocks synaptic transmission in the hippocampus in vitro. Neurosci Lett 91:84-88

Kay AR, Miles R, Wong RKS (1986) Intracellular fluoride alters the kinetic properties of calcium currents facilitating the investigation of synaptic events in hippocampal neurons. J Neurosci 6:2915-2920.

Kleinfeld D, Kahler KH, Hockberger PE (1988) Controlled outgrowth of dissociated neurons on patterned substrates. J Neurosci 8:40984120 .

Luebke JI, Dunlap K, Turner TJ (1993) Multiple calcium channel types control glutamatergic synaptic transmission in the hippocampus. Neuron 11:895-902.

McCobb DP, Best PM, Beam KG (1989) Development alters the expression of calcium currents in chick limb motoneurons. Neuron 2:1633-1643.

Mintz IM, Bean BP (1993) Block of calcium channels in rat neurons by synthetic $\omega$-Aga-IVA. Neuropharmacology 32:1161-1169.

Mintz IM, Venema VJ, Swiderek KM, Lee TD, Bean BP, Adams ME (1992a) Block of P-type calcium channels by the funnel web spider toxin $\omega$-Aga-IVA. Nature 355:827-829.

Mintz IM, Adams ME, Bean BP (1992b) P-Type calcium channels in rat central and peripheral neurons. Neuron 9:85-95.

Muller D, Lynch G (1989) Evidence that changes in presynaptic calcium currents are not responsible for long-term potentiation in hippocampus. Brain Res 479:290-299

Muller D, Oliver M, Lynch G (1989) Developmental changes in synaptic properties in hippocampus of neonatal rats. Dev Brain Res 49: 105-114.

Olivera BM, Rivier J, Scott JK, Hillyard DR, Cruz LJ (1991) Conotoxins. J Biol Chem 266:22067-22070.

Pan ZZ, Tong G, Jahr CE (1993) A false transmitter at excitatory synapses. Neuron 11:85-91.

Parfitt KD, Madison DV (1993) Phorbol esters enhance synaptic transmission by a presynaptic, calcium-dependent mechanism in rat hippocampus. J Physiol (Lond) 471:245-268.

Reynolds IJ, Wagner JA, Snyder SH, Thayer SA, Olivera BM, Miller RJ (1986) Brain voltage-sensitive calcium channel subtypes differentiated by $\omega$-conotoxin fraction GVIA. Proc Natl Acad Sci USA 83 $8804-8807$.

Rivier J, Galyean R, Gray WR, Azimi-Zonooz A, McIntosh JM, Cruz LJ, Olivera BM (1987) Neural calcium channel inhibitors: synthesis of $\omega$-conoloxin GVIA and effects on ${ }^{45} \mathrm{Ca}$ uplake by synaplosomes. J Biol Chem 262:1194-1198.

Rohr S, Scholly DM, Kleber AG (1991) Patterned growth of neonatal rat heart-cells in culture. Circ Res 68:114-130.

Sather WA, Tanabe T, Zhang J-F, Mori Y, Adams ME, Tsien RW (1993) Distinctive biophysical and pharmacological properties of class A (BI) calcium channel $\alpha 1$ subunits. Neuron 11:291-303.

Scholz KP, Miller RJ (1991) Analysis of adenosine actions on $\mathrm{Ca}^{2+}$ 
currents and synaptic transmission in cultured rat hippocampal pyramidal neurones. J Physiol (Lond) 435:373-393.

Scholz KP, Miller RJ (1992) Inhibition of quantal transmitter release in the absence of calcium influx by a $\mathrm{G}$ protein-linked adenosine receptor at hippocampal synapses. Neuron 8:1139-1150.

Scholz WK, Baitinger C, Schulman H, Kelly PT (1988) Developmental changes in $\mathrm{Ca}^{2+} /$ calmodulin-dependent protein kinase II in cultures of hippocampal pyramidal neurons and astrocytes. $\mathbf{J}$ Neurosci 8:1039-1051.

Segal MM (1991) Epileptiform activity in microcultures containing one excitatory hippocampal neuron. J Neurophysiol 65:761-770.

Takahashi T, Momiyama A (1993) Different types of calcium channels mediate central synaptic transmission. Nature 366:156-158.

Thompson SM, Wong RKS (1991) Development of calcium current subtypes in isolated rat hippocampal pyramidal cells. J Physiol (Lond) 439:671-689.

Turner TJ, Adams ME, Dunlap K (1992) Calcium channels coupled to glutamate release identified by $\omega$-Aga-IVA. Science 258:310-313.
Venema VI Swiderek KM, I ee TD, Hathaway GM, Adams MF, (1992) Antagonism of synaptosomal calcium channels by subtypes of $\omega$-agatoxins. J Biol Chem 267:2610-2615.

Wheeler DB, Randall A, Tsien RW (1994) Roles of N-type and Q-type $\mathrm{Ca}^{2+}$ channels in supporting hippocampal synaptic transmission. Science 264:107-111.

Williams K, Russcll SL, Shen YM, Molinoff PB (1993) Developmental switch in the expression of NMDA receptors occurs in vivo and in vitro. Neuron 10:267-278.

Willians ME, Brust PF, Feldman DH, Patthi S, Simerson S, Maroufi A, McCue AF, Velicelebi G, Ellis SB, Harpold MM (1992) Structure and functional expression of an $\omega$-conotoxin-sensitive human $\mathrm{N}$-type calcium channel. Science 257:389-395.

Wu L-G, Saggau P (1994) Pharmacological identification of two types of presynaptic voltage-dependent calcium channels at CA3-CA1 synapses of the hippocampus. J Neurosci 14:5613-5622.

Yaari Y, Hamon B, Lux HD (1987) Development of two types of calcium channels in cultured mammalian hippocampal neurons. Science 235:680-682. 